\title{
Otra pedagogía rizomática como desplazamiento de pensamiento*
}

//Towards a rhizomatic pedagogy as a

movement of thought

Investigaciones $\quad \begin{aligned} & \text { de Educación, N. } 63 . \\ & \text { Segundo semestre de 2012, }\end{aligned}$

//Outra pedagogia de tipo rizomático

como movimento de pensamento

Carlos Alberto Molina Gómez**

Recibido:30/05/2012

Evaluado:05/09/2012

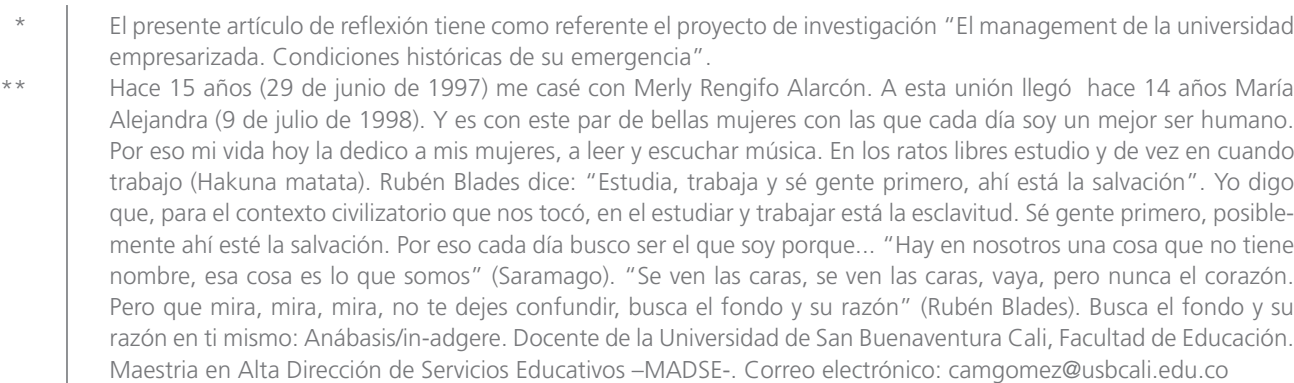

\section{Resumen}

El presente artículo tiene como referente el permanente ejercicio investigativo adelantado a lo largo de dos seminarios doctorales acompañados intelectualmente por el Dr. Alberto Martínez Boom. Estos son: "Pedagogía, escuela y cine" (desarrollado durante el primer semestre del 2011) y "Escuela, subjetividad y estética. Miradas investigativas en tiempos de encrucijada" (desarrollado durante el segundo semestre del 2011). Este artículo propone una reflexión resultado de este extendido ejercicio investigativo desde una perspectiva interpretativa del autor, recurriendo específicamente a las siguientes fuentes: apuntes personales tomados durante todo este año de ejercicio investigativo y de seminario, protocolos de cada sesión de trabajo, producciones finales de cada uno de los seminarios, algunas unidades visuales y algunas literaturantes. Este artículo deja perfilado el siguiente reto/solicitud a quienes nos formamos en educación: avanzar desde el historizar al pedagogizar. Esto es, movimiento, desplazamiento de pensamiento. Se hace alusión de manera directa de otra pedagogía de tipo rizomático donde la voluntad de poder es desplazamiento del pensamiento hacia un sí mismo alejándose del uno mismo. De ahí que se nos aparezca entre sugerente y peligrosa la idea del ser pedagogo. Y para avanzar en este tema es que me apuntalo en la literatura y el cine.

\section{Abstract}

This paper regards ongoing researches derived from two Ph.D. seminars accompanied by thinker Alberto Martinez Boom, as follows: 'Pedagogy, School and Movies' (first semester, 2011) and "School, subjectivity and aesthetics. Research approaches during crossroad times" (second semester, 2011). This also offers a reflection about results from a comprehensive perception by author, particularly based on personal notes taken during that period of researches and seminars, protocols from each session, final documents of each seminar, and some visual and discursive pieces. This gives a new challenge/request to education environment: moving from doing history by doing pedagogy, i.e. a movement/shift of thought. A reference has been made directly to another type of rhizomatic pedagogy where the will is shifting thought towards "him-self" away from "self". Hence a suggestive and dangerous idea of being educator. Therefore literature and movies props up this task.

\section{Palabras Clave}

Pensamiento es desplazamiento, pedagogía de tipo rizomático, campo de visión/pecera, movimiento/trashumancia/itinerancia.

\section{Keywords}

Thought, movement, rhizomatic pedagogy, view focus.

\section{Palavras chave}

Pensamento em deslocamento, pedagogia de tipo rizomático, campo de visão/recipiente, movimento/transhumancia/ itinerância. 


\section{Resumo}

O presente artigo tem como referente o permanente exercício investigativo lançado ao longo de dois seminários doutorais acompanhados intelectualmente pelo Dr. Alberto Martinez Boom. Estes são: "Pedagogia, escola e cinema" (desenvolvido durante o primeiro semestre de 2011) e "Escola, subjetividade e estética. Observações investigativas em tempos de encruzilhada" (desenvolvido durante o segundo semestre de 2011). Este artigo propõe uma reflexão que é resultado desse estendido exercício investigativo a partir de uma perspectiva investigativa do autor, recorrendo especificamente às seguintes fontes: apontamentos pessoais tomados durante todo o ano de exercício investigativo e de seminário, protocolos de cada sessão de trabalho, produções finais de cada um dos seminários, algumas unidades visuais e algumas literaturantes. Este artigo deixa perfilado o seguinte desafio/solicitação aos que nos formamos em educação: avançar do historicizar ao pedagogizar. Este é um movimento, deslocamento de pensamento. Faz-se alusão de maneira direta a outra pedagogia de tipo rizomático, onde a vontade de poder é deslocamento de pensamento até um "si mesmo" distanciando-se "do "eu mesmo". Daí que nos apareça entre sugestiva e perigosa a ideia do ser pedagogo. E para avançar neste tema é que me afianço na literatura e no cinema.

\section{Buscar nuevos mundos buscar un afuera}

\section{Buscar un afuera constituir otro mundo}

Esta reflexión no va en dirección lineal. Al final de la misma posiblemente se podrá identificar una suerte de enmarañamiento o hierba. Y podrá ser así en la medida que como sujeto endouniversitario se derive en estado de alerta', pensándose responsable del propio devenir; de hecho, los seminarios doctorales fueron una invitación a buscar otros mundos, otro campo de visión/pecera ${ }^{2}$ desde la voluntad de poder, desde el flujo continuo de ser el que se es, y a moverse de este campo de visión buscando un afuera, sus irregulares y abismales bordes. No hay formulas, no hay rece-

1 Derivar en estado de alerta es una idea retomada de la conferencia "El acto creativo" de Manfred Max Neef, chileno. Economista y músico. Ganador Premio Nobel Alternativo. Autor de La economía descalza. Conferencia presentada en el Primer Congreso Internacional de Creatividad, Pontificia Universidad Javeriana, Bogotá D.C., 1991: "Mi conclusión a estas alturas, de 77 años de acumulada juventud, es que (...) si viven toda la vida haciendo lo que les conviene, es una vida bastante miserable. Ustedes no tienen que hacer lo que les conviene, ustedes tienen que hacer lo que tienen que hacer. Eso es lo único que les dará la satisfacción cuando lleguen a viejos... haber sido consecuentes consigo mismos. (...) La gente que sabe exactamente para dónde va es la que nunca descubre nada, porque se da lo que llamo la obsesión del punto fijo: estoy aquí y tengo que llegar allá, y en consecuencia, todo lo que hay entremedio se percibe como obstáculos que deben ser superados (...) Y es en esos presuntos obstáculos que está toda la aventura de la vida. Entonces me la paso con anteojeras en una vida pobre. El consejo es derivar en estado de alerta, y derivar no es dejarse llevar por la corriente"

2 Con esta díada se hace referencia explícitamente a una cosmovisión unificadora que produce un mundo y al cual nos sujetamos. Es un adentro. Por eso es campo de visión o una confortable pecera donde existimos y nos movemos creyéndola la realidad o la verdad. En otros escenarios la llamo matrix. Viajar es salirse a los bordes del campo de visión, es desplazarse a los bordes de la matrix para constituir otro mundo dentro del mundo. 
tas, solo hay pretextos para pensarnos. Por eso podría afirmarse la posibilidad del formarse como territorio de pensamiento pero con la alerta de no caer en la trampa de la hollywoodización o la stand-up comedyzación del maestro. De esta manera, se propone una reflexión que le solicita al pensamiento moverse de la pecera de universales de la matrix occidental ${ }^{3}$, buscando, en

3 Con la figura de la pecera de universales de la matrix occidental se hace referencia a la tradición de la modernidad de las abstracciones -lógica de la representación- que subsumen toda diversidad y diferencialidad a universales como: pueblo, nación, Estado, desarrollo, soberanía, nacionalismo. Cfr. "Dos Europas, dos modernidades" y "El regalo envenenado de la liberación nacional" en Imperio de Michel Hardt y Antonio Negri (2005, pp. 89-11; 151-153). De aquí la figura del dentro y del afuera que se mueve en este artículo. El adentro es lo incluido y sujetado a la matrix, es el agua de la pecera. El afuera implica un desplazamiento hacia los bordes de la matrix, hacia las márgenes, su posibilidad todavía incierta. Pertenece al orden de la interiorización, a la dinastía de la representación. El afuera no es ya el espacio clásico y cerrado de la representación, es exterioridad al sujeto, alejándose lo más posible de sí mismo, ponerse fuera de sí mismo pone al descubierto su propio ser: "Este pensamiento que se mantiene fuera de toda subjetividad para hacer surgir como del exterior sus límites, enunciar su fin, hacer brillar su dispersión y no obtener más que su irrefutable ausencia, y que al mismo tiempo se mantiene en el umbral de toda positividad, no tanto para extraer su fundamento o su justificación, cuanto para encontrar el espacio en que se despliega, el vacío que le sirve de lugar, la distancia en que se constituye y en la que se esfuman, desde el momento en que es objeto de la mirada, sus certidumbres inmediatas -este pensamiento, con relación a la interioridad de nuestra reflexión filosófica y con relación a la positividad de nuestro saber, constituye lo que podríamos llamar en una palabra "el pensamiento del afuera". En: Pensamiento del afuera, versión digital en pdf, pp. 7-8. Recuperado de https://docs.google.com/ viewer? $a=v \& q=$ cache:GkZoZ8daNB8J:www.facso uchile.cl/u/download.jsp\%3Fdocument\%3D63$168 \% 26$ property\%3Dattachment \%26index\%3D $2 \% 26$ content $\% 3 \mathrm{D}+\& \mathrm{hl}=$ es\&gl=co\&pid=bl\&srcid= ADGEESg5DoxaF8kRt4HItUNUQFkAQ9ipoqTiBKb PpzAc9g0uZiP7FCYcT-t-HbSIEA01gt-Kz3axePvM8p9eAZYL6yB2GBwJXI-DC1_tLojEpa0-Zg3iBLVa_ FNMAQDzf93ryuc9CRg4\&sig=AHIEtbTOQhadnnP TSaOAAm7ZlhcTaRqBcQ) sus propios bordes, un afuera donde otra vida sueñe... "En estas regiones foráneas, estos hostiles sumideros y páramos intersticiales que los justos ven desde el vagón o el coche, otra vida sueña" (McCarthy, 2006, p. 11), un afuera donde pueda emerger otra subjetivación del ser pedagogo: es una reflexión de posibles búsquedas y salidas a borrascosos bordes: "Estoy hastiado de mi sabiduría como la abeja que ha recogido demasiada miel, tengo necesidad de manos que se extiendan" (Nietzsche, 2006).

En esta pecera se reconoce al maestro que en ciertas condiciones de tiempo y lugar prepara la clase y en otras dicta la clase. En esta dictadura de clase se ha ido expulsando al maestro con su saber y pesan más el Powerpoint, videobeam, los computadores, la tableta, el iPod, el Kindle, el Blackberry, mientras se diluye la figura del maestro ${ }^{4}$. Ya no es necesario saber enseñar. Es suficiente tener una personalidad arrolladora, ser un showman rodeado de Powerpoint, videobeam, tableta,

4 En el artículo del profesor Alberto Martínez Boom titulado "La dilución del maestro" se encuentra este referencia: "La dilución del maestro en la sociedad actual tiene varios significados: dilución como lo que desaparece, lo que se disemina; pero también dilución como ilusión: la que ellos se hacen de sí mismos y la que otros hacen del maestro. La enseñanza que en otra época era definitoria para nombrar al maes tro hoy tiende a remplazarse por una función que puede cumplir cualquier sujeto en muchas instancias y a través de varios dispositivos. Sin duda ese tránsito entre el maestro y la función docente de hoy termina por oscurecerlo, o si lo prefieren, enrarecerlo. Incluso su diseminación es por exceso, no por defecto; tantos son docentes y hay docencia en todo, que el maestro termina por diluirse". Recuperado de http:// palabramaestra.premiocompartiralmaestro.org/ notitotal. php?idn=77\&idt $=6$ 
iPod, Kindle, Blackberry para seducir a los clientes o usuarios. Estanislao Antelo dirá que: "Hoy la docencia se convirtió en un trabajo donde la competencia fundamental parece ser saber relacionarse con el otro, si no sos un ogro" (2009). "Es decir, a la hora de reclutar un docente de hoy pareciera que se le da más importancia a saber quién es antes que lo que sabe enseñar" (2010). Y “...nosotros, los pedagogos, tenemos mucho que ver con eso de haber separado al docente de su oficio" (2007), pues "hoy pesa más la personalidad del maestro que su saber" (2010). Sin embargo, "(...) el afán de agradar está condenado al fracaso" (2007).

Sugerir una pedagogía rizomática es inventar una práctica donde cada quien se haga cargo del ser que es, es inventar otra práctica del ser pedagogo como territorio de pensamiento. $Y$ esto es una batalla de resistencia frente a la dilución del maestro. Resistirse a dilución, hollywoodización o stand-up comedyzación del maestro es ser siendo pedagogo. Es ser siendo pensamiento en flujo, en río. Proseguir su flujo de pensamiento (chemin de pensée) con singular intensidad, pasión, deseo. Esto sería aprender a vivir. Aprender a vivir también es educar, dirá Jacques Derrida. En Ensayo sobre la ceguera, el escritor portugués José Saramago dice: "dentro de nosotros hay algo que no tiene nombre, esa cosa es lo que somos" (Saramago, 2001, p. 354). No es ser siendo comediantes, sino ser viviendo en flujo de ser el que se es. Jugando con las palabras de Martínez Boom, se diría que no se trata del rescate de un pasado ideal de la pedagogía, sino permitirle que emerja con otra potencia que irrumpiendo en el pensamiento posibilite otras formas de pensarse y formarse. Se trataría de darle a la pedagogía la vía del pensamiento (Martínez, 2011, p. 185). Y para ello se solicita viajar al afuera de la pecera para constituir otro mundo siendo el que se es.

A propósito del ser siendo maestro, Jesús Alberto Echeverri Sánchez (1991) advierte que "la profesión de maestro está fracturada, amenazada por decretos y concursos en los que cualquiera puede ser maestro en primaria y secundaria, ¡lo cual es muy grave!". Además, señala que:

Las reformas (educativas) deben centrarse en el maestro, construir un maestro que cargue en su cuerpo y su mente todos los conceptos de la pedagogía. ¡Si no es así, el maestro no podrá hacer transformaciones significativas para la sociedad!, y como vamos se va 
a demorar mucho para

alcanzar ese ideal ${ }^{5}$.

Este inventar una práctica por parte del maestro en la que pueda formarse está diciendo de una pedagogía rizomática. Esta será una pedagogía no de linealidades programadas en planeadores y de maestros que preparan para dictar clase, sino de maestros que se preparan en (posiblemente) la vida. Otra pedagogía rizomática es pedagogía de multiplicidades, de incertidumbres, de extrañamientos, de asombros, de horrores, de acontecimientos y expectante: "A quien no esté en condiciones de provocar horror, hay que rogarle que deje en paz las cuestiones pedagógicas" (Nietzsche, 2000, p. 61). No es de esperar comprensiones, alabanzas o aprobaciones. Solo horrorizar ${ }^{6}$.

$Y$ horrorizarse frente al mundo y la vida que se vive, porque tal como lo diría José Saramago: "No es que sea pesimista, es que el mundo es pésimo" (2005) $\operatorname{sirve}^{\prime \prime}{ }^{8}$. La exigencia es entonces del vivirse para decir quién se es.

5 Recuperado de http://especiales.universia.net co/index2.php?option=com_content\&do $\mathrm{pdf}=1$ \&id $=15705$

6 Horrorizarse frente al mundo y la vida que se vive no es despotismo, intimidación o humillación por el poder del maestro. Sería algo así como no acostumbrase al mundo que es pésimo.

7 ABC.es. (2005) Saramago: «No es que sea pesimista, es que el mundo es pésimo». Hemeroteca. 15-10-2005. Recuperado de: http://www.abc es/hemeroteca/historico-15-10-2005/abc/Ultima/ saramago-no-es-que-sea-pesimista-es-que-elmundo-es-pesimo_611592577475.htm

8 El evangelio de un pesimista. Entrevista con Juan Ramón Iborra publicada en el diario Clarín el domingo 6 de diciembre de 1998. Recuperado de http://edant.clarin.com/suplementos/ cultura/1998/12/06/e-00401d.htm
Desde luego, nosotros no envidiamos a quien se sienta completamente de acuerdo con este presente, y lo acepte como algo "evidente"; en cambio, quien haya llegado al punto de vista opuesto, ya está desesperado, ya no tiene necesidad de combatir $y$, apenas se entregue a la soledad, estará con toda seguridad solo. Sin embargo, en el centro, entre los servidores de lo "evidente" y los solitarios, están los combatientes, es decir, quienes están henchidos de esperanza (Nietzsche, 2000, p. 23).

Ahora bien, cualquiera podría decir que se estaría cabalgando en un ingenuo romanticismo al pretender dejarlo todo a la buena o mala voluntad del maestro tecnoburocrático. De dejarlo todo a un asunto de decisión personal perdiendo de vista un supuesto contexto: desempleo, precariedad laboral, fragmentación social, neoliberalismo. Pero uno de los obstáculos para el desplazamiento del pensamiento es justamente creer que se está condenado a un y por un contexto. Porque se estaría, ahí sí ingenuamente, convencido de un determinismo. No hay tal contexto. Es una multiplicidad de condiciones de posibilidad para que otra vida emerja, para que otro pensamiento emerja. "¡Hay que 
tener pensamientos, y no solo puntos de vista!", alienta Nietzsche (2000, p. 40).

Pero ponerse en camino no es fácil. Salir de la zona de confort no es sencillo. Movilizar el pensamiento es una exigencia. Horrorizarse de la vida que se vive no es cómodo. Ponerse en camino no es un asunto físico de movilidad de un lugar a otro. Es desplazamiento del pensamiento. Moverse no se queda en el acto físico del irse, sino en desafiar el orden establecido y crear prácticas donde otro mundo emerja. Es moverse siendo pedagogo. Es moverse en el asombro, la curiosidad, el ansia y admiración ante otro mundo no pensado ni dado a la razón. ¡Ponte en camino! Podría ser la máxima de esta otra pedagogía rizomática.

Esta sería la exigencia: abrirnos al ser pedagogos formándonos. Y formase sería ponerse en camino, en movimiento, en busca de otra vida, de otro mundo. Y el formarse podría estar en el cine, en la literatura, en la música, en las plásticas, en viajar, en ponerse en camino en busca de..., es moverse en el asombro, la curiosidad, el ansia y admiración ante otro mundo no pensado ni dado a la razón.

Esta otra pedagogía de tipo rizomático como movimiento de pensamiento puede rastrearse en la película La pizarra, de Samira Makhmalbaf, en la que la desestructuración de la sociedad por las guerras civiles se refleja en el movimiento del pensamiento del maestro. Ejemplos se tienen en Johann Heinrich Pestalozzi, quien en la revolución suiza de 1798, como réplica de la Revolución francesa, se va adentrando en el mundo de la educación con los huérfanos de esta guerra y niños pobres de la región. Tras fundar en 1800 un internado educativo en la ciudad de Burgdorf, Pestalozzi es obligado a cerrarlo y se traslada a Münchenbuchsee, y posteriormente a Yverdon-les-Bains (1801). Pero este movimiento no es solo un acto físico de ir de un lugar a otro, sino que está en su pensamiento reformador que se encuentra en sus comunidades autónomas de enseñanza que no dependen del Estado y en sus principios educativos como el de naturalidad y el desarrollo de la observación y hasta en su escritura.

Otro ejemplo se tiene en Antón Semiónovich Makarenko, quien tras el triunfo de la revolución rusa fundó las casas cooperativas para huérfanos de la guerra civil, destacándose la Colonia Gorki. Recuérdese igualmente la revolución china, que mando a los maestros al campo, generando una movilidad y dispersión, 
y mayo del 68 , donde también se ve cómo la conmoción social permite un desplazamiento de la pedagogía institucional.

La película La pizarra es una metáfora de ese viaje de los maestros que tiene su correlato en las experiencias antes narradas de Pestalozzi, Makarenko, la revolución china y mayo del 68 . Pero esto no sugiere un viaje físico, aunque no lo descarta, que dependa de condiciones adversas sociopolíticas. No es el viaje o el desplazamiento por condiciones de violencia política. Es un viajar desde el adentro de la matrix a sus bordes para constituir otro mundo. $Y$ en viajar está el formarse, pues es aprender a vivir para decir quiénes somos. No caería mal recordar aquí la figura de Florentino Ariza en la novela El amor en los tiempos del cólera, de Gabriel García Márquez.

Tanto en la película como en las experiencias antes citadas, la idea de moverse, de irse a los bordes, es fuerte y constante. Moverse a los bordes no se queda en el acto físico de irse al campo y crear las colonias agrícolas, como Pestalozzi y Makarenko, sino en desafiar el orden establecido creando experiencias educativas para que la niñez pobre y desamparada, víctima de la guerra, se forme. Es mover el pensamiento para ser pedagogo. $Y$ esto no está determinado por ningún contexto.

De esta otra pedagogía de tipo rizomático como movimiento de pensamiento podría emerger otro posible reto: ponerse en camino es vivirse, acudir a la voluntad de poder contra la voluntad del poder. $Y$ esto es: no dejarnos entrampar en la forma humano, abrirnos al ser hombre, mujer $\mathbf{u}$ otra identidad. El mayor reto de vivir es ser hombre, mujer u otro. La forma humano es una forma de ser hombre o mujer, pero no es la única forma de serlo. Ha habido y habrá otras formas de ser hombre o mujer (porvenir). El problema o forma humano nos limita. Y la educación es para el bien de ese humano, por eso lo empequeñece, lo reduce, lo minimiza. Se es demasiado humano, pero poco hombre o mujer. Se es voluntad de poder, placer, deseos, instintos y emociones. La Forma humano limita. Bajo la forma humana:

La gente dice frases vacías y estúpidas que reflejan sus temores y esa insustancial visión del mundo que prevalece hoy en tantos grupos, la dictadura de la asepsia verbal e ideológica y física, dios, ese deseo de ahogar la animalidad que tiene el cuerpo... (Gamboa, 2009, p. 382).

Puede ampliarse este reto con un (extenso) fragmento de la novela De sobremesa de José Asunción Silva:

¿La vida real?... Pero ¿qué es la vida real, dime, la vida burguesa sin emociones y $\sin$ curiosida- 
des?... en cuanto a mi vida de hoy (...) su organización obedece en el fondo a lo que ha constituido siempre mi aspiración más secreta, mi pasión más honda: el deseo de sentir la vida, de saber la vida, de poseerla (...) ¿Tú crees que yo me acostumbro a vivir?... No, cada día tiene para mí un sabor más extraño y me sorprende más el milagro eterno que es el Universo. La vida. ¿Quién sabe lo que es? (...) ¿Tú crees que la mayor parte de los que se mueren han vivido? Pues no lo creas; mira, la mayor parte de los hombres, los unos luchando a cada minuto por satisfacer sus necesidades diarias, los otros encerrados en una profesión, en una especialidad, en una creencia, como en una prisión que tuviera una sola ventana abierta siempre sobre un mismo horizonte, la mayor parte de los hombres se mueren sin haberla vivido, sin llevarse de ella más que una impresión confusa de cansancio!... ¡Ah! Vivir la vida... eso es lo que quiero, sentir todo lo que se puede sentir, saber todo lo que se puede saber, poder todo lo que se puede... (...) ¡Ah! ¡Vivir la vida! Emborracharme de ella, mezclar todas sus palpitaciones con las palpitaciones de nuestro corazón antes de que él se convierta en ceniza helada; sentirla en todas sus formas... (Silva, 2009, pp. 24-31).

Con José Asunción Silva se puede decir que la fuerza de ser hombre o mujer es la que hay que dirigir, controlar, planificar. La violencia que se requiere para de ser hombre o mujer hay que planificarla, regularla. Para "que la fuerza pueda todo lo que puede" debe ser dirigida. Para ello entra la alta dirección, la gestión. La alta dirección controla, dirige, administra, planifica esa voluntad de poder desde la voluntad del poder (noopolítica ${ }^{9}$ ). Entra la voluntad del poder sobre la voluntad de poder. Y esto tiene todo que ver con la pedagogía rizomática, pues es la pedagogía del viaje del adentro de la matrix hacia sus borrascosos bordes para constituir un mundo en donde se pueda sentir todo

9 Si las disciplinas moldean hábitos principalmente en la memoria corporal, en las sociedades de control modulan la memoria espiritual. En estos términos, el concepto de noopolitica (de noos, o noûs que designa en Aristóteles la parte más alta del alma, el intelecto, y, por otro lado, también refiere al nombre de un proveedor de acceso a Internet), denominación adoptada por el italiano Mauricio Lazzarato, será el más adecuado para dar cuenta del conjunto de las nuevas técnicas de control. Existiría, así, un moldeamiento de los cuerpos, asegurado en los espacios de disciplinamiento (prisiones, escuela, fábrica); por otra parte, la gestión de la vida organizada por las medidas biopolíticas (políticas estatales en salud, vivienda, seguros previsionales, etc.); y, finalmente, la modulación de la memoria regulada por la noopolítica (a partir de las redes tecnológicas audiovisuales, el marketing y constitución de la opinión pública) (Pincheira, 2010). 
lo que se puede sentir, saber todo lo que se puede saber, poder todo lo que se puede. Es decir, otro mundo donde se pueda ser el que se es. Esto va más allá de las oficinas de planeación, de los sistemas de gestión de calidad, de las normas ISO, del Icontec y de las lógicas de organización de la vida.

Va más allá de la voluntad del poder que limita organizando la fuerza, la voluntad de poder, el yo puedo, el deseo, el placer, los instintos, las emociones, la vida, bajo la dirección y gestión. Se limita el ser superiores. Por eso no hay educación superior, pues se limita el ser superior al profesionalizar, dirigir y administrar la vida. Lo superior de lo que se llama educación superior no está en un escalón más de ilustración del homínido superior, sino en sentir todo lo que se puede sentir, saber todo lo que se puede saber, poder todo lo que se puede para que otra vida sueñe en el afuera de la matrix.

Se entiende voluntad de poder como voluntad de otra perspectiva, voluntad de otro campo de visión, voluntad de colocarse en otro lugar (águila y serpiente ${ }^{10}$ ), voluntad del afuera. Esa voluntad de poder, voluntad del afuera, se puede expresar así:

El mejor modo de vivir con plenitud la vida es llevándola a los límites, asomando la cara a sus más profundos abismos, a su periferia, a sus socavones y palacios derruidos, solo así tendremos el cuerpo caliente y la cabeza hirviendo de sueños, me quedo aquí (...) No quiero regresar a ese sueño de opio que es

10 Inteligencia y orgullo: "Cuando el sol estuvo en el mediodía, miró (Zaratustra) interrogativamente a lo alto; porque, por encima de él, oía la llamada clara y nítida de un pájaro. $Y$ he aquí que un águila describía amplios círculos en el aire, y de ella colgaba una serpiente, no como una presa sino como una amiga: pues el águila la tenía enroscada en tomo a su cuello" (Nietzsche, 2006). "Un mediodía, mientras Zaratustra le está hablando a su corazón, descubre que "un águila trazaba amplios círculos en el aire y de ella colgaba una serpiente, pero no como una presa, sino como una amiga, pues se mantenía enroscada en su cuello". El círculo que traza el águila "es el símbolo -comenta Heidegger- del eterno retorno, pero un girar en círculos que al mismo tiempo se eleva hacia lo alto y en lo alto se mantiene". La serpiente, el animal más inteligente, está enroscada en el cuello del animal más orgulloso, reforzando el simbolismo del anillo del eterno retorno. El orgullo poco tiene que ver con la mera arrogancia o la vacua presunción. El orgullo es la fuerza que nos empuja hacia arriba, alejándonos de lo que hay de inferior en nosotros... precisamente porque hay algo superior en nosotros que nos reclama. La inteligencia y el orgullo se pertenecen mutuamente mientras se elevan en círculos bajo el sol del medio día". Recuperado de http://elcafedeocata.blogspot.com/2009/02/los-animalesde-zaratustra.html 
nuestro paraíso del norte, yo me quedo aquí, con la gente real y los problemas reales, donde todos deben subir al trapecio sin red y la lucha por la existencia es verdadera y no una metáfora; aquí encontré la vida, he comprendido el valor de esa cosa milagrosa y frágil que es la vida y por eso me han entrado unas ganas avasalladoras de vivirla, de agotarla hasta el último grano, qué milagro (Gamboa, 2009, pp. 433-435).

La voluntad del poder de la alta dirección en la universidad dirige y gestiona el pensamiento profesionalizando. La alta dirección es una organización de la voluntad de poder preparando para el trabajo: profesionaliza. Este es el objetivo último de la cultura extensiva (y mercantilizada): profesión y laboriosidad. "Trabaje duro y sea buena gente", rezaba una propaganda de Sidoc S.A. ${ }^{11}$ en Cali.

De ahí la educación expansiva. Educar en cuanto sea posible a humanos corrientes que no se bajen de la buseta, del $\mathrm{MIO}^{12}$ o del Transmilenio ${ }^{13}$. Y muchos de nosotros inocentemente y de buena fe no solo subimos a otros a la buseta, sino que hace rato estamos en ella.

El reto es producirse como pensamiento que no sea el de los burócratas, ni el de los expertos, ni el de las instituciones. Mover pensamiento hacia los bordes de la matrix es distanciarse de la burocracia institucional, estatal, de la burocracia administrativa para que ese viajar hacia los bordes haga corriente, haga flujo, haga vida, se forme como el que se es contra la educación extensiva que formatea para el uno mismo, para el deber ser cliente o usuario.

En fin, la pedagogía rizomática solicita un viaje del adentro de la matrix hacia sus bordes para saltarlos y dejar que otra vida sueñe alejada de las gramáticas de la organización de la vida que se pasea tan campantemente hoy en las universidades profesionalizando humanos para que sean productivos y no sean cuando crecidos (cosa que no se logra) el juguete vulgar de las pasiones, pero sí esclavos serviles de los tiranos:

11 La Siderúrgica de Occidente, Sidoc S.A., es una empresa colombiana que fabrica y comercializa aceros estructurales de alta calidad con un alto compromiso hacia la excelencia, el medio ambiente y el desarrollo social. Recuperado de http://www. sidocsa.com/inicio.html

12 Así se llama el privado sistema de transporte urbano masivo en la ciudad de Santiago Cali, Colombia

13 Así se conoce el sistema privado de transporte urbano masivo de Bogotá, capital de Colombia. 
estudia, trabaja y sé gente primero, ahí está la salvación. Una propaganda de la Institución Universitaria Politécnico Grancolombiano dice: "Alcanza tus metas sin descuidar tus obligaciones"14. Lo que aquí se sugiere es que la obligación que no podemos descuidar es vivirse. Las otras obligaciones pueden esperar.

\section{Ponerse en camino salir en búsqueda de viajar}

Ponerse en camino es paso del adentro al afuera. El adentro rígido, inflexible, normalizado, controlador y afuera lo inesperado, la pesadez del camino, la incertidumbre de una búsqueda que no tiene certezas, ni seguridades, no hay programaciones previas. El ponerse en marcha enseña que salir es maravillarse con el mundo, es disfrutar el viaje, es dejar la normas y las comodidades del adentro para gozar la vida.

El viajar es la gran salida, es el camino al afuera, es avanzar a los bordes. Pero... ¿Lo que mueve el pensamiento es un adentro desestructurado o la inquietud de un afuera incalculado? ¿Qué afuera convoca como maestros para moverse desde y en el campo de visión?

Ahí estaría la fuerza de la pedagogía rizomática: como pragma del vivirse. Flujo de pensamiento vivi-

14 Recuperado de http://estudiaenelpoli. poligran.edu.co/posgradovirtual/index. php?seccion=ClickMagic\# do con singular intensidad, pasión, deseo. Pedagogía rizomática sería, para quienes gustan de las definiciones y certezas, aprender a vivirse. Aprender a vivirse es educarse. En esta fuerza está lo sugerente y lo peligroso, porque constituye otro mundo irreductible, contrahegemónico y contraconductual. Es otro mundo en los bordes de la pecera, en el afuera. En palabras de Alberto Martínez, en contextos de contingencia e inmanencia de la otra pedagogía, la rizomática, no hay aula, hay pluricidad de posibilidades que alteran el pensamiento lineal y parametrizado. Jugando con las palabras de José Saramago, el mundo de la pecera está todo aquí adentro como lo afirma la mujer del médico en la novela Ensayo sobre la ceguera. Así que "yo me voy. (...) Tomó la maleta, me voy" (Saramago, 2001, pp. 436438) porque "he despertado con la intención de hacer maletas y largarme pase lo que pase. No me importa si mis carceleros ponen el grito en el cielo" (Alzate, 2007, p. 33).

Para ampliar esta sugerencia de la fuerza de la pedagogía rizomática como pensamiento que es ponerse en camino... como pensamiento que sale en búsqueda de... se dejan insinuadas dos ideas:

Otra pedagogía rizomática. Su fuerza está justamente en la posibilidad de ser territorio de pensamiento, o mejor, ser posibilidad de encuentro de mundos. Entendiendo mundo no como totalización, sino como elaboraciones vitales del existir, en 
batallas contra el anonimato, la homogenización y la estandarización a la que someten estados y regímenes que significan representación y abstracción. Es salida de las teorías. La pecera occidental piensa y habla desde y con teorías, desde marcos teóricos. Habla con y desde representaciones: pueblo, nación, Estado, soberanía, sí mismo, uno mismo, humanidad. Otras civilizaciones no occidentales piensan mundos. Por ejemplo: Occidente piensa piedras, minerales, montañas y nacimientos de agua como recursos naturales. Un nasa o un misak piensan la cuna del mundo y la morada de sus dioses. James Cameron nos ilustra esto con Avatar. Pero no se trata de ver quién es mejor o si tal o cual está en lo cierto o tiene la verdad. Esta sería la postura dicotómica de la pecera occidental. Sencillamente son otra cosa. No hay un mundo verdadero y dado a la razón, sino pluralidad de mundos, como elaboraciones vitales del existir, cada vez más plurales e irreductibles. El mundo no es uno, es muchos mundos.

Los muros de la escuela son asaltados por el afuera. La pecera no es homogénea, no es una aplanadora, no es totalizante. Tiene fisuras, tiene ranuras, no es compacta. Por ahí se cuela la conciencia individual. A pesar de la regulación suceden cosas. La regulación y el control no son totales ni absolutos, pues hay disfrutes del tiempo desde abajo, tiempos del goce: volarse de clase, escurrirse para contestar el celular, el papelito que circula entre los estudiantes o el mensaje de texto que se envían por el celular, la risa burlona cuando el maestro da la espalda. Este es el afuera irreprimible, no sujetable. El afuera no es solo calle o el después de las rejas o después de la puerta. Es tiempo y goce en la escuela por fuera de la escuela. Hay un tiempo para gozar, ese es el tiempo del mundo del afuera que no es tiempo de la escuela así estemos en ella. El tiempo que se goza es tiempo que se reprime. La pecera no nos tiene totalmente. Este afuera desafía los muros de la escuela. El afuera violento, irreprimible, no sujetable, demente, se cuela por entre los muros. Se mete y distorsiona, causa ruido, desajusta, moviliza, el afuera es incertidumbre. Es lo inédito, potente y hasta riesgoso del espíritu de hombres y mujeres no entrampados totalmente en el adentro. El asunto se complica cuando la pecera quiere regular, controlar el goce y el placer. Cuando pretende meter el goce, placer y deseo en el circuito de la producción y el consumo. Cuando se intenta hacer pasar el placer y el goce por el orden de las cosas que se administran, se gestionan, se planifican, se contabilizan. 
De lo uno a lo otro es el gran tema de la metafísica. Todo el trabajo de la razón humana tiende a la eliminación del segundo término. Lo otro no existe: tal es la fe racional, la incurable creencia de la razón humana. Identidad = realidad, como si, a fin de cuentas, todo hubiera de ser, absoluta y necesariamente, uno y lo mismo. Pero lo otro no se deja eliminar; subsiste, persiste; es el hueso duro de roer en que la razón se deja los dientes. Abel Martín, con fe poética, no menos humana que la fe racional, creía en lo otro, en "la esencial heterogeneidad del ser", como si dijéramos en la incurable otredad que padece lo uno ${ }^{15}$.

Ahora se puede avanzar en una posible relación del ponerse en camino... del salir en búsqueda de... con el investigar.

Permanentemente, los seminarios con el maestro Alberto Martínez interpelan no solo frente a la voluntad de poder, sino frente a la

15 Antonio Machado. En: Juan de Mairena. Sentencias, donaires, apuntes y recuerdos de un profesor apócrifo. Recuperado de http://jaserrano.nom.es/Machado/Guerra.htm voluntad de investigar. Y la principal interpelación está relacionada con la idea del viaje... viaje que implica ampliar el campo de visión. Para este caso, poner en suspenso la ontologización del mundo o las cosas del mundo como cosas pensadas por una conciencia abriéndose a lo irreductible, violento y transgresor de los hechos cotidianos que se resisten/niegan a dejarse modelar y moldear por representaciones universales.

Así como no hay un pensamiento único, totalitario y hegemónico, pues se termina estrellando con la posibilidad de mundos cada vez más plurales, tampoco se puede restringir el hacer historia de las prácticas pedagógicas a ontologizaciones o pensamientos únicos que estandarizan y explican todo llevando a la zona de confort y del menor esfuerzo, pues es así y lo dijo la ciencia. Por ejemplo, investigar las prácticas de dirección y gestión en la universidad empresarizada dándola como hecho dado o acabado o como representación inamovible. O investigar los placeres o sufrimientos de los docentes universitarios asumiendo al docente como verdad dada y fija en el tiempo. Si se busca la escuela o la pedagogía como objetos acabados con seguridad se encontrará la escuela y la pedagogía; si se va a buscar el docente, el placer o el sufrimiento como objetos dados, de seguro se encontrará el docente, el placer y el sufrimiento. Es decir, en la investigación tradicional común- 
mente se trabaja con objetos ya formados que asumimos como verdades inamovibles que se vuelven conocimiento y desde las que se hace ciencia (ej.: conciencia-conocimiento-ciencia). Pero pocas veces esta investigación pone en duda o cuestiona el objeto universidad, el objeto docente, el objeto placer, el objeto sufrimiento o el objeto escuela yendo río arriba mostrando la emergencia de discursos que por la fuerza de la vox pópuli se vuelven saberes a partir de los cuales se conoce y se hace ciencia (ej.: prácticas discursivas-saberes-ciencia).

Si la pedagogía hoy, como se sugiere aquí, se hace desde la contingencia e ironía de la vida misma con sus demenciales hechos, la investigación de las prácticas pedagógicas también puede coger por otro camino que no sea el de la palabra ya dicha y llevada al altar de los libros oficiales. Puede coger por el camino de otros espacios, tiempos, sujetos y discursos no estrictamente educativos (Martínez, 1995, p. 4). De ahí la idea del viaje para aproximarnos a los barrancos, para llegar a las fronteras de lo dicho y volver sobre lo no dicho o sobre lo dicho pero prohibido, excluido o no validado con el criterio de verdad.

Una pedagogía rizomática de extrañamientos y expectante en los bordes de la pecera como pragma del vivirse solicita una indagación de prácticas pedagógicas también en movimiento, dejando en suspenso los universales y abriéndose a incertidumbres y contingencias que se muestran en prácticas y discursos.

$\mathrm{Y}$ para pensarse como investigadores desde esta reflexión, podría preguntarse: ¿Qué tan rizomático es el viaje del investigador? Martínez Boom lo coloca en la siguiente pregunta: “QQué movimientos de pensamiento se han producido y se están produciendo en el investigar?". Y subraya citando a Deleuze: "Todo pensamiento es un desplazamiento" (Martínez, 2011). Pero ipor qué tanta insistencia en el desplazamiento del campo de visión? ¿En el desplazamiento de lo trascendente hacia lo acontecimental irreductible e infranqueable?

Para el caso de la historia de las prácticas pedagógicas, moverse dentro y desde el campo de visión solicita trepar las explicaciones comunes y corrientes que da la historiografía lineal de la escuela o la pedagogía o de la universidad y hurgar, auscultar lo no dicho y lo no visto en la cotidianidad para hacerlo evidente. Más aún es poder ver en lo evidente y cotidiano los rasgos ocultos que no dejan ver los discursos y prácticas hegemónicas. En otras palabras, es el esfuerzo del pensamiento por no estar 
satisfecho con lo que le dicen y lo que le muestran y atreverse a hurgar por sí mismo y develar lo oculto. Se podría llamar a esto estar en desasosiego para ponerse a andar en busca de...

Añadamos otra discusión a partir de la gramática dominante en nuestro campo de visión/pecera. La discusión sobre lo que denominamos contexto. En este desplazamiento, el contexto no es causalidad o determinismo. Lo que se tiene es un cruce irregular de relaciones, una trama de condiciones de existencia, posibilidad y resolución, pero que no determina ni condiciona nada. Porque si determinara y condicionara, como se dice del contexto, entonces se estaría condenado de por vida sin posibilidad de mover el pensamiento, no habría posibilidad de otra pedagogía rizomática.

Si se acepta esta idea, se podría aceptar que la pedagogía rizomática es posible, ya que no habría condicionamiento ni determinación. Precisamente porque el campo de visión no es homogéneo, sino que tiene sus fisuras, es que es posible movilizar el pensamiento, es posible formarse viviendo en viaje a un afuera de la pecera. El tiempo del goce de la vida emerge de entre las fisuras que tiene la pecera. Por ello es posible otra pedagogía rizomática, porque no hay determinismos.

Por ejemplo, el poder. Está en las relaciones y no en un lugar específico. El poder no es un asunto instalado en un lugar jerárquico, en una clase social, en un gremio o en una oficina, sino que está dentro de y entre las relaciones sociales. El poder, así visto, no está afuera, sino dentro, en los enunciados, dentro y entre las relaciones, y no en la exterioridad de un aparato burocrático o jerárquico.

La jerarquización determina las distancias entre los seres, pero en ella no está instalado el poder. El poder está en las prácticas discursivas que se realizan en un momento dado. Las relaciones de poder son relaciones que no se ven y que pueden ser solicitadas o rechazadas por los individuos. En el primer caso se generan relaciones de dependencia, aunque no total, pues el ser humano no es una cosa que siempre se queda ahí en el mismo lugar y sin moverse, sino que cambia, muta; $y$ en el segundo caso, se generan relaciones de contrapoderes, fuerza contra fuerza. En los dos casos, las relaciones de poder se dan entre individuos libres. Por eso no podemos trivializar el poder reduciéndolo a jerarquías, a gobiernos, a personas o regímenes.

¿Cómo entendemos entonces condiciones de existencia y posibilidad? Cuando se dice condición se hace referencia explícita a determinar una marcación o zona de relaciones, pero no como determinación/causa de lo que sucede ahí en dicha zona; no son condiciones de causalidad o de determinación o de afectación, sino multiplicidad de fuerzas que posibilitan al emergen- 
cia de un objeto. Determinación no es condición. Volviendo a los ejemplos anteriores, sería: ¿Qué condiciones posibilitaron la emergencia de lo que hoy se nos muestra tan naturalizado y evidente como la universidad empresarizada? $\mathrm{O}$ ¿qué condiciones posibilitaron la emergencia de lo que hoy se nos muestra tan naturalizado y evidente como placer y sufrimiento en la vida laboral del docente universitario? Esto es otra cosa a decir: "Placer y sufrimiento en la vida laboral del docente universitario", o decir "prácticas de dirección y gestión en la universidad empresarizada".

Siendo así las cosas, no debemos buscar en el contexto las causas de... o la explicación de tal o cual hecho. El pensar bajo la lógica de las intencionalidades o de las condiciones contextuales como determinación de... se convierte en un obstáculo para movernos del campo de visión/pecera y ampliarlo. Es un obstáculo asumir que el contexto explica todo y que en el contexto están las explicaciones y causas de todo. La posibilidad de hacer historia mostrando cómo emergen saberes que hoy se dan como verdades naturalizadas, a partir de las cuales se conoce y se hace ciencia, se halla en las condiciones que posibilitan un entrecruce de relaciones específico que no necesariamente está inscrito en la linealidad del tiempo. Las condiciones son relampagueantes, aleatorias, discontinuas.

Las condiciones de posibilidad son fuerzas que se cruzan, pero sin linealidad. En lo determinado todo está dado y no hay nada que hacer. En las condiciones de posibilidad hay aún espacio para la extrañeza. Hablar de condiciones de posibilidad es estar ante la política del aún... lo aún no dicho, explicado, comprendido. Política del aún... ¿Cómo decir cosas de manera distinta a partir no del contexto como causa condicionante, sino a partir de condiciones de posibilidad?

En la manera de hacer historia convencional se encuentran otros obstáculos para el pensamiento como:

Obstáculo del deber ser. Se abandona la incalculabilidad por ir tras el deber ser teleológico. Pensamos siempre en términos de lo que debe ser y no de lo que es. La investigación se hace en términos de deseables perfectibles y no en términos de hurgar y escarbar para dejar ver lo que somos, lo que es. En el deber ser hay un fuerte campo de visión judeocristiano. Idea del más allá. Esperanza, sin evidencias, de una salva- 
ción. En el deber ser se promete y se desea sin evidencias.

Obstáculo de los antecedentes. Todo tiene un pasado inmediato, mediato o lejano, pero lo tiene. Es el principio de causalidad. En el pasado se encuentra todo lo que explica el presente, pues es una cadena de hechos conectados linealmente. En el auge de la espiritualidad pop se Ilama sincrodestino. El destino está irremediablemente sincronizado con un contexto, con un pasado, $y$ con un por-venir, hasta con leyes físicas. Entonces no es mucho el margen de maniobra, pues todo está sincrodestinado.

Obstáculo de la ideología. Se piensa en términos de campo de visión. Todo está sometido al yugo de la ideología y a una trama secreta de las ideologías sobre los hechos. Todos los hechos se dan porque hay una corriente ideológica que los formatea para que sean así. Y por lo tanto las ideologías son un escudo para explicar todo el orden, y con esa explicación hay conformidad. Por eso no se actúa como ser libre, sino como víctima de las ideologías y hay autoesclavitud. Las ideologías, al igual que el poder, se encarnan. Somos nosotros las que las hacemos realidad. No es un orden externo que se imponga desde fuera y que someta o subyugue a menos que se le permita.

Obstáculo de la ley. Lawrence Lessig afirma categóricamente "el código es la ley". Pues bien, se va detrás de esta afirmación al explicar todo en términos de leyes, códigos, manuales, decretos, actos legislativos. Se confina la historia a la ley. Para justificar o explicar los hechos se acude a la ley como bien superior que ordena y regula todo y que da cuenta de todo. Salirse de la ley, no para delinquir, sino para ver en lo prohibido condiciones de posibilidad, es un reto para el pensamiento.

Para ir esquivando estos obstáculos se propone ir río arriba. Es decir, volver a los hechos; no dejar en el olvido los acontecimientos que no han sido explicados, no dejarlos caer en la trampa del olvido por la rutina o porque ya la verdad ha sido dicha o está en los libros.

Inconclusión. La voluntad de poder en otra pedagogía rizomática para sentir todo lo que se puede sentir, saber todo lo que se puede saber, poder todo lo que se puede en lucha contra el uno mismo.

Se propone una inconclusión, pues no se pretende cerrar nada. Concluir es cerrar, y aquí no cerramos nada. ¿Qué queda? Solo se dejan algunas ideas sueltas, como ha sucedido a lo largo del texto, para que cada quien asuma su vida.

Con esto se dice que transitar de la producción de deseo a la constitución de deseo no implica, ni sugiere, ni reclama una dialéctica o una confrontación, ni se para en un espíritu belicoso o guerrerista. En lo que insiste es en la sentencia de Cormac McCarthy en Suttree: "Henos aquí en un mundo dentro del mundo. (...) otra vida sueña". (McCarthy, 2004, p. 11). Esa "otra vida sueña" es la re-existencia o, parafraseando 
a Foucault, el gobierno de sí mismo. El gobierno de sí se propone, es crear un mundo dentro del mundo. No es guerrerismo, no es belicosidad, no es confrontación. Pero sí puede implicar lucha consigo mismo para salirse del formato, para dejarlo todo y largarse como lo propone Gabriel Jaime Alzate en su novela $E l$ viajero en el umbral: "He despertado con la intención de hacer maletas y largarme pase lo que pase. No me importa si mis carceleros ponen el grito en el cielo" (Alzate, 2007, p. 33), o como lo dice Cipriano Algor, personaje de La caverna de José Saramago, quien con voz firme decía: "Vosotros decidiréis vuestras vidas, yo me voy. (...) Tomó la maleta, me voy, dijo" (Saramago, 2003, pp. 436-438).

A propósito, Humberto Quiceno, haciendo referencia a la epistemología como "lo que hacía el filósofo antiguo", señala: "que además no solo se dedicaba a pensar, sino a cuidar de su vida y de su estilo de vida. El que se dedica a la episteme (la invención y la crítica) no es cualquier hombre, es un hombre libre, ético y un hombre que habla del bien como una acción, un hacer y una práctica". (Quiceno, 2011, p. 16) Saramago lo pone en los siguientes términos: "El asunto no es para mañana ni para el mes que viene, cuando llegue el momento usted decidirá entre ir o quedarse, su vida es suya..." (Saramago, 2003, p. 87).

Con esto se deja esbozada la idea final. La constitución de deseo sería dedicarse a cuidar de la vida, es tener un propio estilo de vida porque mi vida es mía, pero alejada de las técnicas de gestión de la vida que impone el capitalismo occidental. Aquí está la lucha y el tránsito. Una cosa es cuidar de la vida dentro del canon acudiendo a las retóricas del cuidado de sí del capitalismo globalitario y otra es trabajarse a sí mismo por fuera y alejado de estas retóricas.

Pero, "tal como sucede en las vidas, cuando creíamos que nos habían quitado todo, y de pronto descubrimos que nos queda algo". Y ese algo es lo inédito en cada uno de nosotros. Emerge la política del aún. Lo aún no planificado, ni administrado, ni capturado por el imperio. $Y$ es en ese aún donde hay que trabajar. La propuesta es dejarse acontecer por la vida para... mundaneidad no mundana...

Entonces, lo que está en juego es la emergencia de la subjetivación, del magma de pasiones y deseos como construcción ético-estética, porque como lo afirma Paul Virilio "la medida del mundo es nuestra libertad" (1997, p. 45). Y es el mismo Virilio 
quien pone sobre aviso de este magma cuando dice que "el mundo está antes dentro de nosotros que fuera. Pero si realmente está fuera, en la geografía y en el espacio-mundo, también existe a través de mi conciencia del mundo". "El mundo está todo aquí dentro" lo diría José Saramago en su Ensayo sobre la ceguera. Así que, más que desasosiego, lo que hay es un reto personal por desplazar mi pensamiento desde mis pasiones y deseos como constitución ético-estética: lograr construir el ser que quiero ser. Esto podría ser otra pedagogía rizomática.

Cipriano Algor se ha preguntado cómo es posible que se haya dejado encerrar durante tres semanas sin ver el sol y las estrellas, a no ser, forzando el cuello, desde un trigésimo cuarto piso con ventanas que no se podían abrir, cuando tenía aquí este río, es cierto que maloliente y menguado, este puente, es cierto que viejo y mal cuidado, y estas ruinas que fueron casas de personas, $y$ el pueblo donde había nacido, crecido y trabajado, con su carretera cruzándolo y la plaza a un lado (Saramago, 2003, pp. 439440).

\section{Referencias}

ABC.es. (2005) Saramago: «No es que sea pesimista, es que el mundo es pésimo». Hemeroteca. 15-10-2005. Recuperado de: http://www.abc.es/hemeroteca/historico-15-10-2005/abc/ Ultima/saramago-no-es-quesea-pesimista-es-que-el-mundoes-pesimo_611592577475.html

Alzate Ochoa, G. (2007). El viajero en el umbral. Bogotá: Alcaldía Mayor de Bogotá. Secretaría de Cultura, Recreación y Deporte.

Antelo, E. (2005). Notas sobre la incalculable experiencia de educar. Recuperado de www. estanislaoantelo.com.ar/index. php?/textos/articulos/

Antelo, E. (2009). La tarea del docente no es comprender a los niños. Entrevista realizada por Carolina Porley. Montevideo. 22 de octubre del 2009. Recuperado de http://www.estanislaoantelo.com.ar/files/entrevistamontevi.pdf

Antelo, E. (2010). Hoy pesa más la personalidad del maestro que su saber. Entrevista realizada por Marcela Isaías para La Capital. Sábado 29 de mayo del 2010. Recuperado de http:// www.lacapital.com.ar/ed_educacion/2010/5/edicion_68/contenidos/noticia_5020.html

Antelo, E. (2007). Los docentes, su oficio y la enseñanza. Entrevista diario El Popular. Olavarría. Provincia de Buenos Aires, 
2007. Recuperado de http://www.elpopular.com.ar/diario/2007/10/28/nota.html?idnota=9891

Echeverri Sánchez, J. (1991). La escuela en el cine y la literatura: recuerdos de un espectador. Educación y Cultura, 24.

Gamboa, S. (2009). Necrópolis. Colombia: Editorial Norma.

Galeano Quiroz, M. \& Echeverri Sánchez, J. (2008). Especial para Universia Colombia. Recuperado de http:// especiales.universia.net.co/index2.php?option=com content\&do_pdf $=1 \& i d=15705$

Martínez Boom, A. (2008). La escuela: un lugar para el común. En Educar, posiciones acerca de lo común (pp. 189-208). Buenos Aires: Del Estante.

Martínez Boom, A. (2010a). Alteraciones y diluciones en la educación de hoy. En Educar, saberes alterados (pp. 113133). Buenos Aires: Del Estante.

Martínez Boom, A. (2010b). Dilución del maestro. Palabra Maestra, 25. Recuperado de http://palabramaestra.premiocompartiralmaestro.org/notitotal.php?idn=77\&idt=6)

Martínez Boom, A. (2011). La enseñanza como posibilidad del pensamiento. Bogotá: Editorial Magisterio y GHPP.

Martínez Boom, A. \& Álvarez, A. (Comp.). (2010). Figuras contemporáneas del maestro en América Latina. Bogotá: Editorial Magisterio y GHPP.

Martínez Boom, A. \& Peña, F. (Comp.). (2009). Instancias y estancias de la pedagogía. La pedagogía en movimiento. Bogotá: Editorial Bonaventuriana.

Molina Gómez, C. (2011a). Apuntes personales del seminario pedagogía, escuela y cine, Doctorado Interinstitucional en Educación, sede Universidad Pedagógica Nacional, Bogotá.

Molina Gómez, C. (2001b). Civilización y ethos. Cavilaciones en torno al contexto civilizatorio. Cali: Editorial Bonaventuriana.

Molina Gómez, C. (2011c). Expedición hacia el interior. Cali: Editorial Bonaventuriana.

Molina Gómez, C. (2012). El management no es como lo pintan. Cali: Editorial Bonaventuriana.

McCarthy, C. (2006). Suttree. Barcelona: De Bolsillo.

Nietzsche, F. (2000). Sobre el porvenir de nuestras institucio- 
nes educativas. Barcelona: Tusquets.

Nietzsche, F. (2001). Cómo el "mundo verdadero" acabó convirtiéndose en una fábula. Historia de un error. En el crepúsculo de los ídolos. Madrid: Alianza Editorial.

Nietzsche, F. (2006). Así habló Zaratustra. Madrid: Alianza Editorial.

Quiceno Castrillón, H. (2011). Epistemología de la pedagogía. Cali: Ediciones Pedagogía y Educación.

Saramago, J. (2001). Ensayo sobre la ceguera. Bogotá: Alfaguara.

Saramago, J. La caverna. Bogotá: Alfaguara. Silva, Jose Asunción. (2009). De sobremesa. Alcalá la Real: Alcalá Grupo Editorial Virilio, P. (1997). El cibermundo, la política de lo peor. Madrid: Teorema. 